\title{
ESTUDO DO TRATAMENTO TÉRMICO DE COMPÓSITOS DE MATRIZ METÁLICA DA LIGA AA7075 COM REFORÇO PARTICULADO CERÂMICO DE ALUMINA
}

\section{*Lorene Ester Fernandes, Elton Italo Vieira Xavier, Michelle Maria Perez Lott, Moisés Euclides da Silva Junior, Diogo Monteiro do Nascimento and Oscar Olimpio de Araujo Filho}

Mechanical Engineering Department, Federal University of Pernambuco, Cidade Universitária, Recife 50740-540

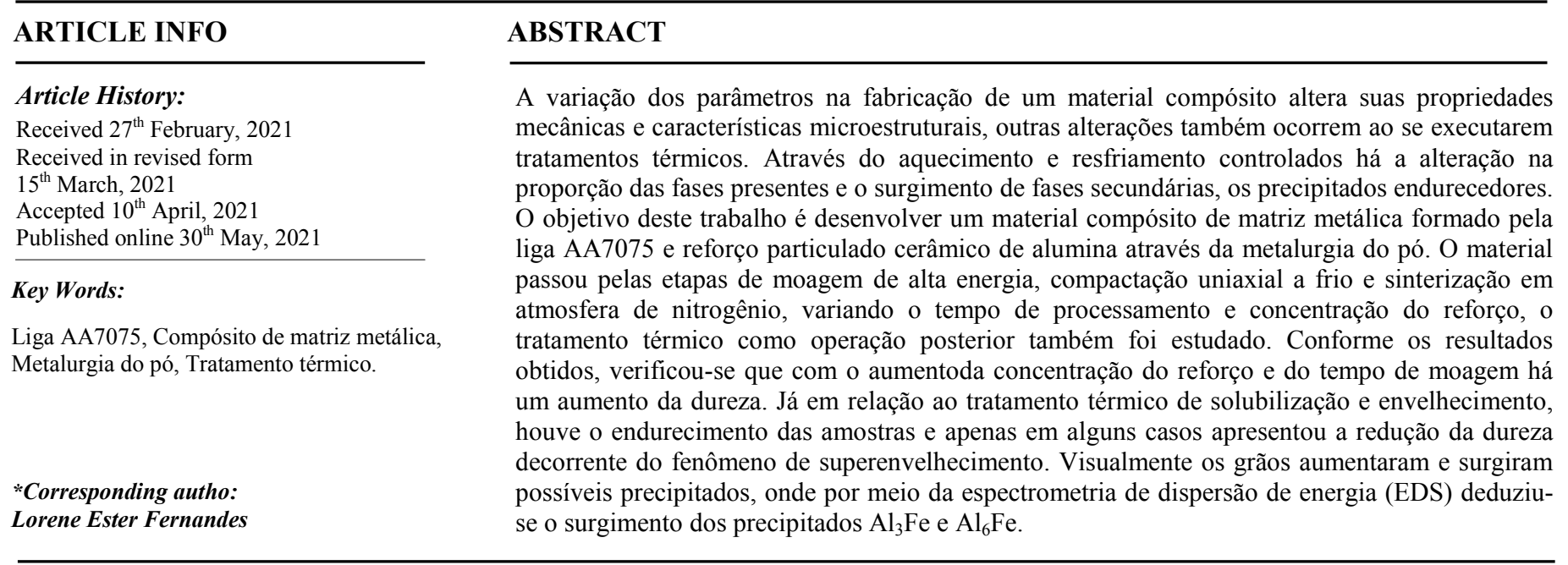

Copyright $\odot$ 2021, Lorene Ester Fernandes et al. This is an open access article distributed under the Creative Commons Attribution License, which permits unrestricted use, distribution, and reproduction in any medium, provided the original work is properly cited.

Citation: Lorene Ester Fernandes, Elton Italo Vieira Xavier, Michelle Maria Perez Lott, Moisés Euclides da Silva Junior, Diogo Monteiro do Nascimento and Oscar Olimpio de Araujo Filho, 2021. "Estudo do tratamento térmico de compósitos de matriz metálica da liga aa7075 com reforço particulado cerâmico de alumina", International Journal of Development Research, 11, (05), 47167-47173.

\section{INTRODUÇÃO}

Atualmente, devido ao desenvolvimento tecnológico e necessidades do mercado as pesquisas científicas no campo dos materiais vêm se desenvolvendo em desenvolver materiais alternativos. Muitas dessas tecnologias modernas precisam de materiais com combinações incomuns de propriedades mecânicas, tais como: ductilidade e resistência ao desgaste, estas combinações são de difícil obtenção pelos metais, cerâmicas e polímeros convencionais. (Callister, 2012). Os materiais compósitos são uma alternativa a essa problemática. Estes são obtidos pela combinação entre materiais de diferentes classes e contêm no mínimo duas fases distintas, uma fase contínua, denominada matriz e uma fase dispersa, chamada de reforço. $\mathrm{O}$ compósito produzido se caracteriza por apresentar uma combinação das propriedades da matriz e do reforço. (Callister, 2012). Um dos processos de produção de compósitos de matriz metálica é a metalurgia do pó (MP), um processo metalúrgico que produz peças a partir de pós-metálicos e não metálicos, estes são compactados em uma forma definida e aquecidos abaixo do ponto de fusão. A fabricação de componentes pela MP pode melhorar o desempenho do produto final, e apresenta vantagens como uma maior precisão dimensional e melhor controle de composição. (Araujo Filho, 2006; Araujo Filho, 2016; Chiaverini, 1992).
Quando utilizada junto com a moagem de alta energia (MAE) a MP possibilita processar metais muito difíceis de serem obtidos pelos processos convencionais, além de conseguir uma coesão na combinação de materiais com baixa solubilidade entre si, como no caso dos compósitos de matriz metálica. (Suryanarayana, 2001). Embora a técnica já obtenha peças com formas e dimensões finais, é comum realizar operações complementares com a finalidade de melhorar as propriedades mecânicas e as tolerâncias dimensionais. A mais comum é o tratamento térmico, que altera as propriedades físicas e mecânicas, sem alterar a composição química do material. Para as ligas de alumínio o tratamento de solubilização e envelhecimento tem finalidade de gerar o aumento de dureza pela precipitação de fases endurecedoras. (Chiaverini, 1992; Barbosa, 2014). Utilizar a metalurgia do pó na produção de compósitos de matriz metálica de liga de alumínio AA7075 com reforço cerâmico de Alumina e sua posterior complementação com o tratamento térmico de solubilização e envelhecimento buscando melhorar as propriedades da liga em estudo é o objetivo do presente trabalho.

\section{MATERIAIS E MÉTODOS}

Obtenção do Compósito por Moagem de Alta Energia: O material compósito foi desenvolvido a partir de pós ligados da liga AA7075 e 
do pó do óxido de alumínio. Foram fabricadas $12 \mathrm{~g}$ de cada pó compósito, sendo a composição do reforço nas amostras variando entre $5 \%$ e $15 \%$. Ao todo foram fabricadas 9 amostras, para as três composições do reforço e para os três tempos de moagem a serem estudados (30min, $60 \mathrm{~min}$ e $120 \mathrm{~min}$ ), os pós de partida foram pesados com uma balança de precisão de 1 miligrama. Em cada amostra foi adicionado $2 \%$ de ácido esteárico, utilizado como agente controlador do processo, funcionando como um lubrificante e evitando que o pó e fique preso nas esferas (Suryanarayana, 2001). A Tabela 1 apresenta as amostras fabricadas. Ao todo foram fabricadas 9 amostras, para as três composições do reforço e para os três tempos de moagem a serem estudados (30min, 60min e $120 \mathrm{~min}$ ), os pós de partida foram pesados com uma balança de precisão de 1 miligrama. Em cada amostra foi adicionado $2 \%$ de ácido esteárico, utilizado como agente controlador do processo, funcionando como um lubrificante e evitando que o pó e fique preso nas esferas (Suryanarayana, 2001). A Tabela 1 apresenta as amostras fabricadas.
Caracterização dos Compósitos Sinterizados: As amostras sinterizadas e tratadas termicamente foram caracterizadas por microcopia ótica (MO), MEV, EDS e MicrodurezaVickers (HV). Previamente foi realizada a preparação metalográfica com corte de seções superficiais e transversais, lixamento, polimento com pasta de diamante de $3 \mu \mathrm{m}$ e $1 \mu \mathrm{m}$ e ataque químico com ácido fluorídrico a $0,5 \%$. Na MO foram obtidas micrografias das seções superficiais e transversais do compósito com e sem tratamento térmico, com ampliações de 50x, 100x, 200x, 500x e 1000x, para cada um dos sinterizados. As técnicas de MEV e EDS foram realizadas apenas nas amostras com Tratamento Térmico, onde foram obtidas micrografias com ampliações de 1000x, 2000x, 3000x, 4000x e 5000x, além da análise de composição feita em 3 regiões relevantes na amostra pelo EDS. Para análise das propriedades mecânicas foram realizados ensaios de MicrodurezaVickers. Nas amostras com e sem Tratamento Térmico foram realizadas 5identações em cada seção com carga 0,4 kgf durante $15 \mathrm{~s}$.

Tabela 1. Definição das amostras fabricadas. (Autores, 2019)

\begin{tabular}{|c|c|c|c|c|}
\hline \multirow{2}{*}{ AMOSTRA } & \multicolumn{3}{|c|}{ COMPOSIÇÃO DAS AMOSTRAS } & \multirow{2}{*}{ TEMPO DE MOAGEM } \\
\cline { 2 - 4 } & MATRIZ (AA 7075) & REFORÇO (ALUMINA) & ÁCIDO ESTEÁRICO & \\
\hline 1 & $95 \% * 12 \mathrm{~g}=11,4 \mathrm{~g}$ & $5 \% * 12 \mathrm{~g}=0,6 \mathrm{~g}$ & $2 \% * 12 \mathrm{~g}=0,2 \mathrm{~g}$ & $30 \mathrm{~min}$ \\
\hline 2 & $95 \% * 12 \mathrm{~g}=11,4 \mathrm{~g}$ & $5 \%{ }^{*} 12 \mathrm{~g}=0,6 \mathrm{~g}$ & $2 \% * 12 \mathrm{~g}=0,2 \mathrm{~g}$ & $60 \mathrm{~min}$ \\
\hline 3 & $95 \% * 12 \mathrm{~g}=11,4 \mathrm{~g}$ & $5 \% * 12 \mathrm{~g}=0,6 \mathrm{~g}$ & $2 \% * 12 \mathrm{~g}=0,2 \mathrm{~g}$ & $120 \mathrm{~min}$ \\
\hline 4 & $90 \% * 12 \mathrm{~g}=10,8 \mathrm{~g}$ & $10 \% * 12 \mathrm{~g}=1,2 \mathrm{~g}$ & $2 \% * 12 \mathrm{~g}=0,2 \mathrm{~g}$ & $30 \mathrm{~min}$ \\
\hline 5 & $90 \% * 12 \mathrm{~g}=10,8 \mathrm{~g}$ & $10 \% * 12 \mathrm{~g}=1,2 \mathrm{~g}$ & $2 \% * 12 \mathrm{~g}=0,2 \mathrm{~g}$ & $60 \mathrm{~min}$ \\
\hline 6 & $90 \% * 12 \mathrm{~g}=10,8 \mathrm{~g}$ & $10 \% * 12 \mathrm{~g}=1,2 \mathrm{~g}$ & $2 \% * 12 \mathrm{~g}=0,2 \mathrm{~g}$ & $120 \mathrm{~min}$ \\
\hline 7 & $85 \% * 12 \mathrm{~g}=10,2 \mathrm{~g}$ & $15 \% * 12 \mathrm{~g}=1,8 \mathrm{~g}$ & $2 \% * 12 \mathrm{~g}=0,2 \mathrm{~g}$ & $30 \mathrm{~min}$ \\
\hline 8 & $85 \% * 12 \mathrm{~g}=10,2 \mathrm{~g}$ & $15 \% * 12 \mathrm{~g}=1,8 \mathrm{~g}$ & $2 \% * 12 \mathrm{~g}=0,2 \mathrm{~g}$ & $60 \mathrm{~min}$ \\
\hline 9 & $85 \% * 12 \mathrm{~g}=10,2 \mathrm{~g}$ & $15 \% * 12 \mathrm{~g}=1,8 \mathrm{~g}$ & $2 \% * 12 \mathrm{~g}=0,2 \mathrm{~g}$ & $120 \mathrm{~min}$ \\
\hline
\end{tabular}

Para a obtenção do pó compósito foi utilizada a moagem de alta energia em um moinho vibratório do tipo SPEX. No moinho a jarra de aço inox foi carregada com a amostra, com $120 \mathrm{~g}$ de esferas também de aço inox (BPR de 10:1) e com álcool isopropílico, este tem a finalidade de evitar a combustão espontânea do pó de alumínio. (Bezerra Júnior et al., 2014). Após o respectivo tempo de moagem a mistura do pó com o álcool foi levada a uma estufa para a completa secagem do álcool, restando apenas o pó compósito.

Caracterização dos Compósitos: As técnicas de microscopia eletrônica de varredura (MEV) e espectroscopia de energia dispersiva (EDS) foram realizadas nas amostras de pó para avaliar a morfologia e composição química dos mesmos. No MEV foram obtidas micrografias de 100x, 200x, 500x, 1000x, 1500x, 2000x. O EDS foi realizado a partir da micrografia com ampliação de 2000x e foi obtida uma análise dos elementos encontrados em 3 regiões diferentes da amostra.

Compactação e Sinterização dos Pós Compósitos: Após a obtenção dos pós compósitos seguiu-se o processamento pela metalurgia do pó com a compactação uniaxial a frio. O pó foi compactado e densificado numa forma denominada de compactado verde em uma matriz com furo concêntrico e com a utilização de uma prensa hidráulica, foram compactadas 2 amostras com $4 \mathrm{~g}$ de pó para cada combinação de parâmetros de estudo e utilizada uma pressão de 7,0 ton $/ \mathrm{cm}^{2}$. Após obtenção do compactado verde seguiu-se para etapa de sinterização. Esta etapa foi realizada em forno a vácuo com atmosfera de nitrogênio $\left(\mathrm{N}_{2}\right)$ e foram utilizados temperatura de sinterização de $500^{\circ} \mathrm{C}$ com tempo de patamar de $5 \mathrm{~h}$.

Tratamento Térmico de Solubilização e Envelhecimento: Para cada combinação de concentração de reforço e tempo de moagem uma das amostras passou pelo Tratamento Térmico. O tratamento selecionado foi a Solubilização e Envelhecimento Artificial denominado T6. Em um forno mufla as amostras foram solubilizadas a uma temperatura de $480{ }^{\circ} \mathrm{C}$ durante $90 \mathrm{~min}$, seguido de têmpera em água à temperatura ambiente, caracterizando uma alta taxa de resfriamento. Em seguida foi realizado o envelhecimento a $120{ }^{\circ} \mathrm{C}$ durante $180 \mathrm{~min}$, seguido de resfriamento lento ao ar calmo. (Barbosa, 2014)

\section{RESULTADOS E DISCUSSÃO}

MEV e EDS dos Pós Compósitos: Na análise das micrografias do MEV dos pós compósitos processados observou-se claramente que com o aumento do tempo de moagem o tamanho de partícula dos pós ficavam cada vez menores, o comportamento foi o mesmo para todos os pós fabricados e pode ser observado para o pó com $5 \%$ de reforço na Figura 1. Vários autores como Xavier et al. (2019) e Morais (2018) também relataram o mesmo comportamento de redução da granulometria com o aumento do tempo de moagem. Em seu trabalho Morais (2018) utiliza uma técnica granulométrica para concluir que a partir de um tempo de moagem a redução do tamanho das partículas tende a se estabilizar. Analisando as micrografias da Figura 1 pode-se perceber uma redução menor do pó processado por 60min para o de $120 \mathrm{~min}$ do que a redução observada no de $30 \mathrm{~min}$ para o de $60 \mathrm{~min}$, verificando de forma qualitativa a tendência à estabilidade na redução do tamanho de partícula relatada pelo autor. Também na Figura 1 observa-se que independente do tempo de moagem todos os pós compósitos obtidos apresentaram morfologia irregular e achatada, este formato é comumente encontrado em pós processados pela técnica de moagem de alta energia. (Araujo Filho et al., 2017). Da análise de EDS dos pós, mostrada em três regiões distintas na Figura 2, foi observada a presença dos principais elementos químicos do compósito, exceto pelo presença do Ferro (Fe), visto na Figura 2(a) como partículas de coloração esbranquiçada. Na Figura 2(b), a região analisada apresenta Alumínio (Al) e Oxigênio (O) com uma coloração cinza mais escura e em menor quantidade o que pode-se caracterizar como a presença do reforço particulado de Alumina $\left(\mathrm{Al}_{2} \mathrm{O}_{3}\right)$. Já a Figura 2(c) a composição encontrada apenas de Alumínio ( $\mathrm{Al}$ ) na região cinza mais clara e em maior quantidade, representa as partículas da matriz da liga AA7075. Observa-se que a quantidade de partículas brancas cresce com o aumento do tempo de processamento do pó, Figura 1, levando ao entendimento que essas amostras foram contaminadas por Ferro (Fe) decorrente do contato do material processado com a jarra e as esferas de aço inox utilizadas na moagem. Souza e Peres (2016) citam o material da jarra e das esferas utilizadas na moagem como uma potencial fonte de contaminação para o material processado. 


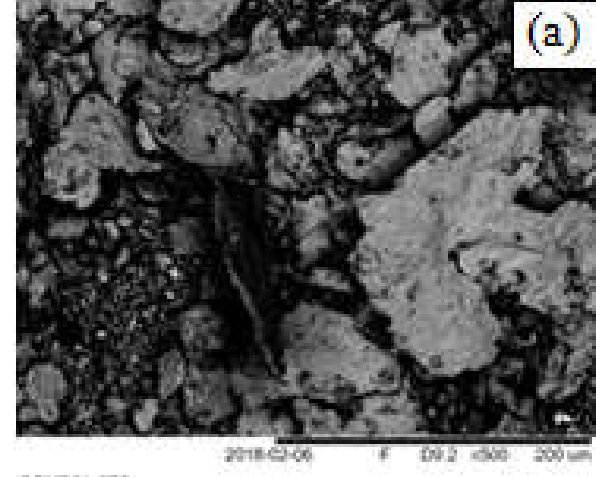

orveretro

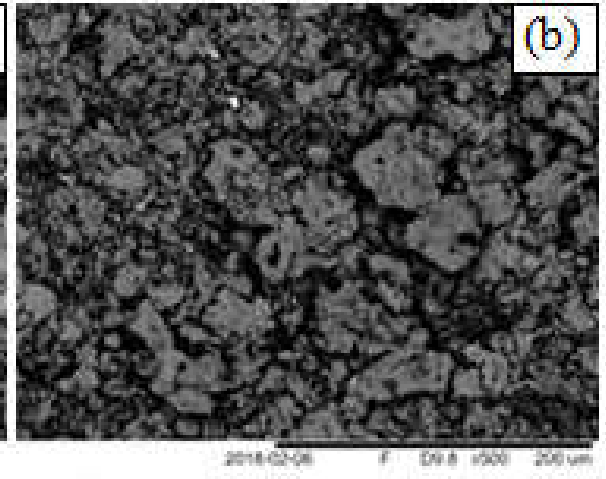

bevelcicta

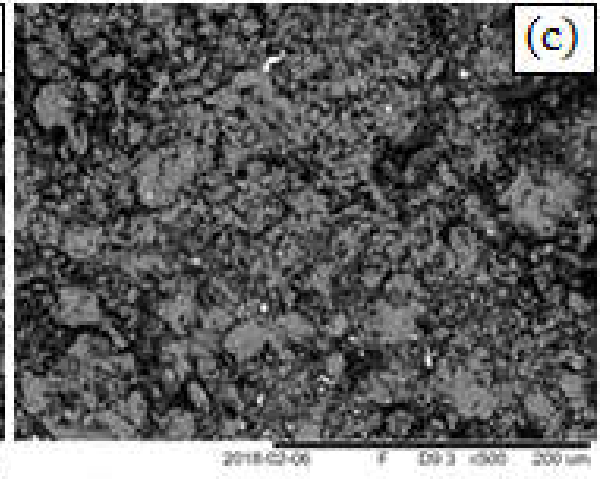

otuteicto

Figura 1. Micrografias do MEV do pó compósito de matriz AA7075 e reforço de 5\% de Alumina. (a) 30min de MAE; (b) 60min de MAE ; (c)120min de MAE. (Autores, 2019)
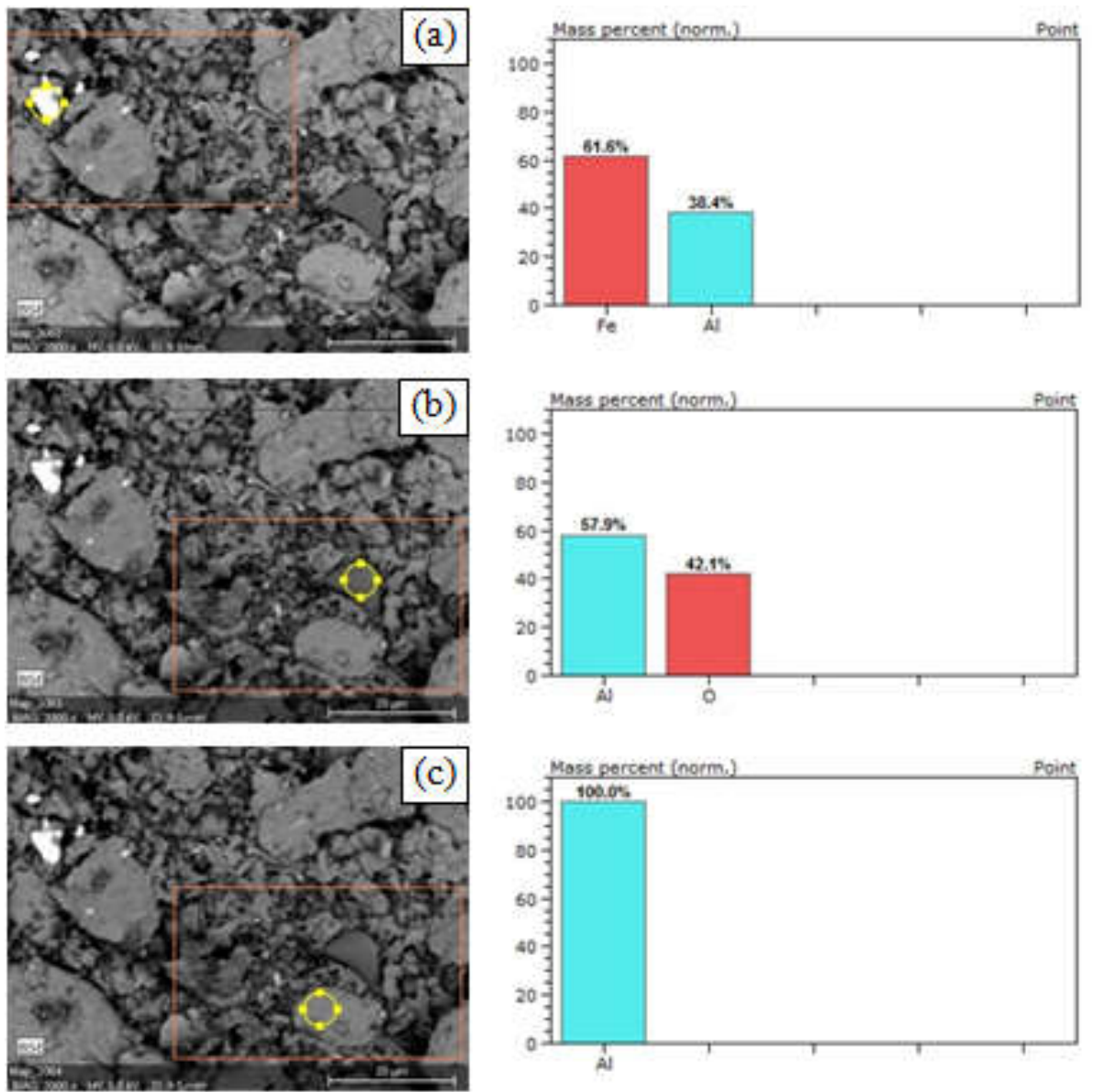

Figura 2. EDS do pó compósito de matriz AA7075 e reforço de 5\% de Alumina. (a) região 1; (b) região 2; (c) região 3. (Autores, 2019)
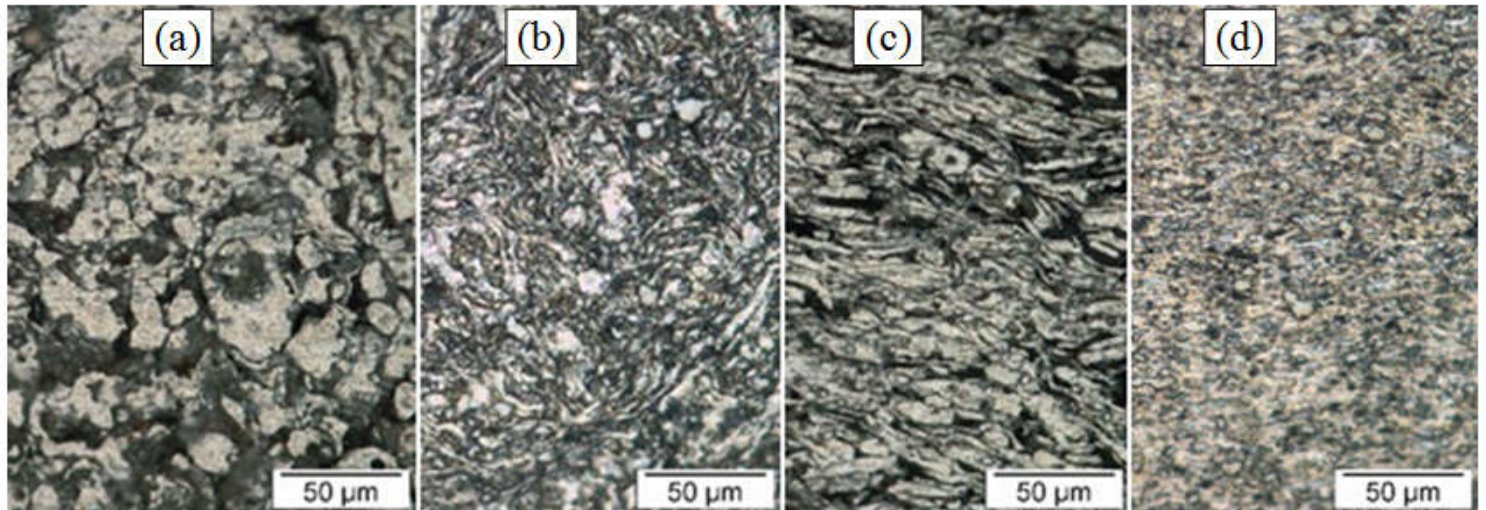

Figura 3. MO do compósito sinterizado com reforço de 5\% de Alumina sem tratamento térmico. (a) 30min de MAE, seção superficial; (b) 120min de MAE, seção superficial; (c) 30min de MAE, seção transversal; (d) 120min de MAE, seção transversal. (Autores, 2019) 
MO dos Sinterizados Com e Sem Tratamento Térmico: Nas micrografias da MO das amostras compactadas e sinterizadas sem o tratamento térmico, observadas nas Figuras 3 e 4, visualiza-se uma distribuição equilibrada do reforço na matriz e a estrutura lamelar principalmente na seção transversal. A estrutura lamelar é característica de materiais que passaram pela sequência de MAE e MP durante o processamento (Araujo Filho et al., 2017). Quanto maior o tempo de processamento na MAE menor o tamanho das partículas de pó e consequentemente a estrutura lamelar se apresenta mais deformada, com as lamelas cada vez mais finas. Para as amostras com $120 \mathrm{~min}$ de processamento na MAE, quase não se visualizou mais as lamelas.
Nas micrografias das amostras que passaram pelo tratamento térmico de solubilização e envelhecimento, vistas nas Figuras 5 e 6, percebese visualmente que com a aplicação do tratamento, houve um crescimento dos grãos. As mesmas continuaram com a estrutura lamelar com maior incidência na secção transversal.

MEV e EDS dos Sinterizados Tratados Termicamente: Complementando a análise microestrutural das amostras tratadas termicamente, a MEV reforça o que já foi levantado nas analises anteriores da MO, a medida que o tempo de processamento na MAE aumenta o tamanho dos grãos diminuem e a estrutura lamelar prevalece.
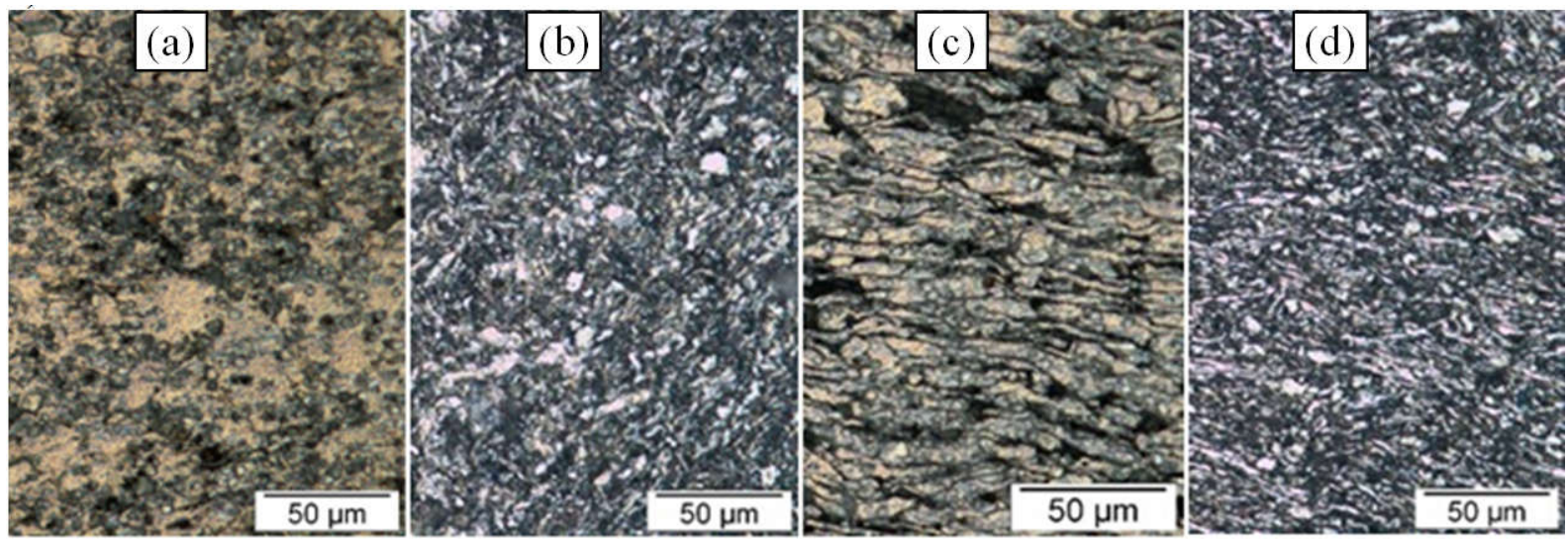

Figura 4. MO do compósito sinterizado com reforço de $10 \%$ de Alumina sem tratamento térmico. (a) 30min de MAE, seção superficial; (b) 120min de MAE, seção superficial; (c) 30min de MAE, seção transversal; (d) 120min de MAE, seção transversal. (Autores, 2019)
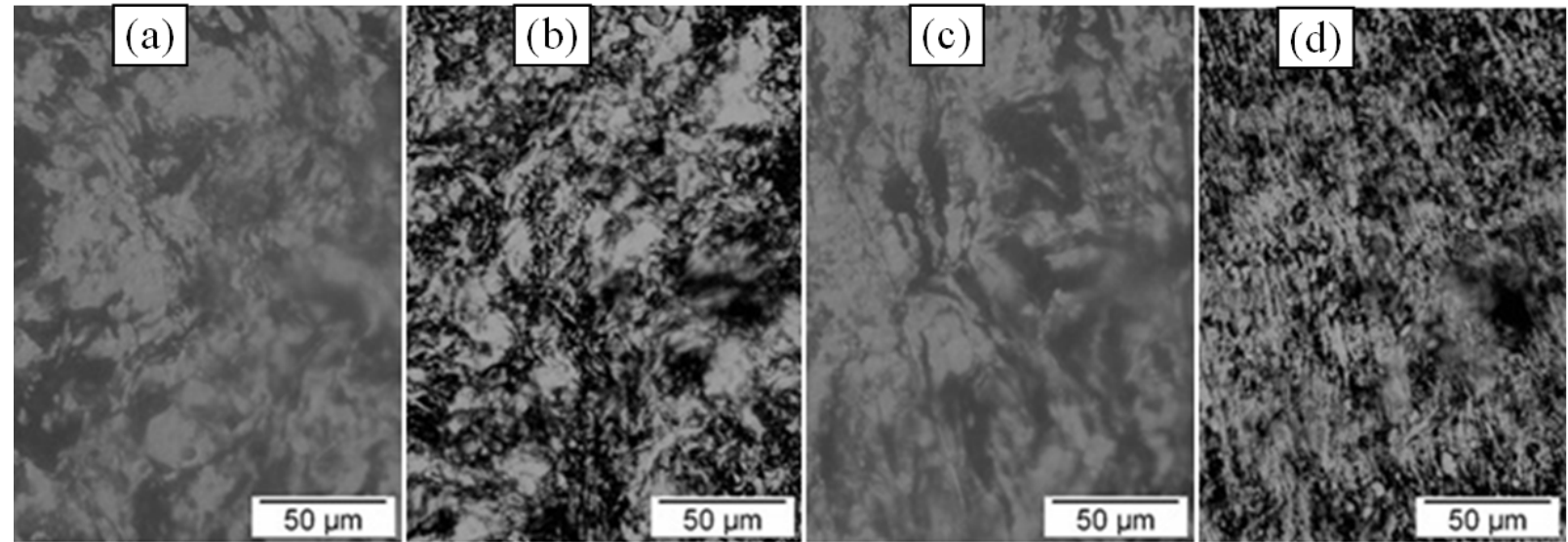

Figura 5. MO do compósito sinterizado com reforço de 5\% de Alumina com tratamento térmico. (a) 30min de MAE, seção superficial; (b) 120min de MAE, seção superficial; (c) 30min de MAE, seção transversal; (d) 120min de MAE, seção transversal. (Autores, 2019)
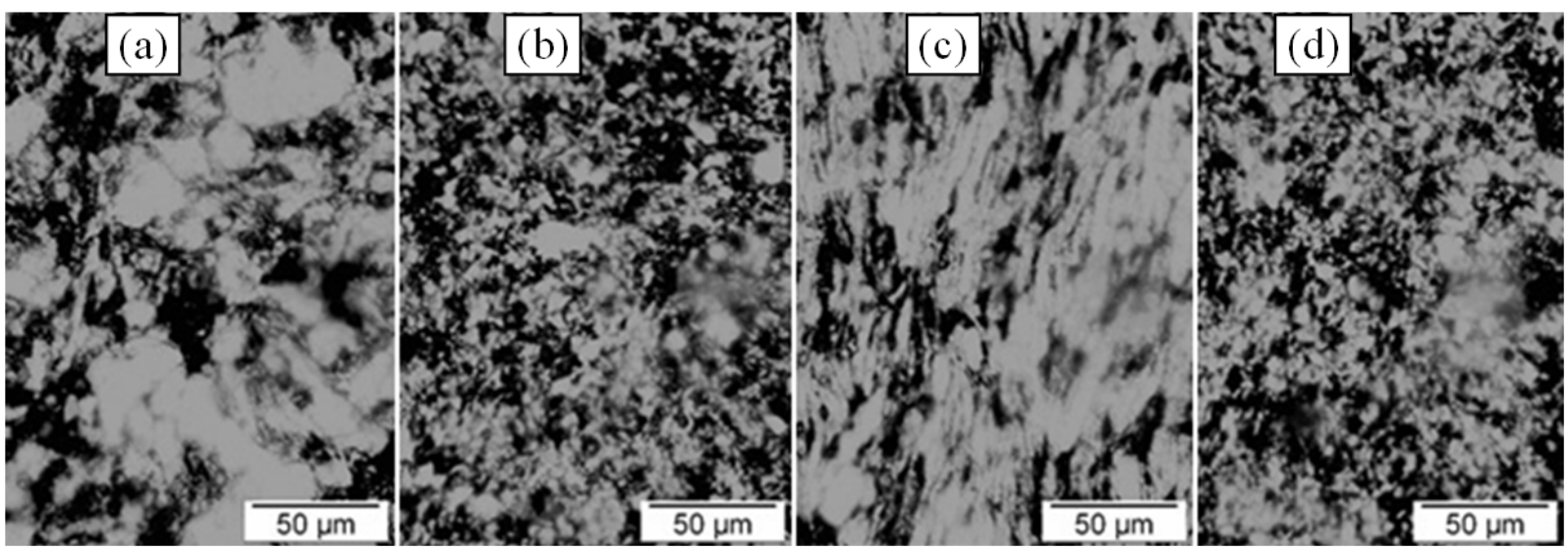

Figura 6. MO do compósito sinterizado com reforço de $10 \%$ de Alumina com tratamento térmico. (a) 30min de MAE, seção superficial; (b) 120min de MAE, seção superficial; (c) 30min de MAE, seção transversal; (d) 120min de MAE, seção transversal.

(Autores, 2019) 
Nas micrografias, mostradas nas Figuras 7 e 8, as lamelas aparecem mais claramente para os baixos tempos de processamento e observase a presença no sinterizado dos grãos esbranquiçados, com contaminação de Ferro (Fe), e vistos anteriormente nos pós compósitos processados. Visto que o Tratamento de Solubilização e Envelhecimento visa a geração de precipitados endurecedores, a análise do EDS busca identificá-los.
Na Figura 9, analisa um grão cinza mais escuro composto basicamente por Alumínio ( $\mathrm{Al})$ e Oxigênio $(\mathrm{O})$, característico do reforço particulado de Alumina $\left(\mathrm{Al}_{2} \mathrm{O}_{3}\right)$, mesma condição visualizada no MEV dos pós compósitos. Nas Figuras 10 e 11 foi analisada a região branca das amostras. Apesar do EDS do pó compósito obtido já detectar a presença/contaminação de Ferro (Fe),
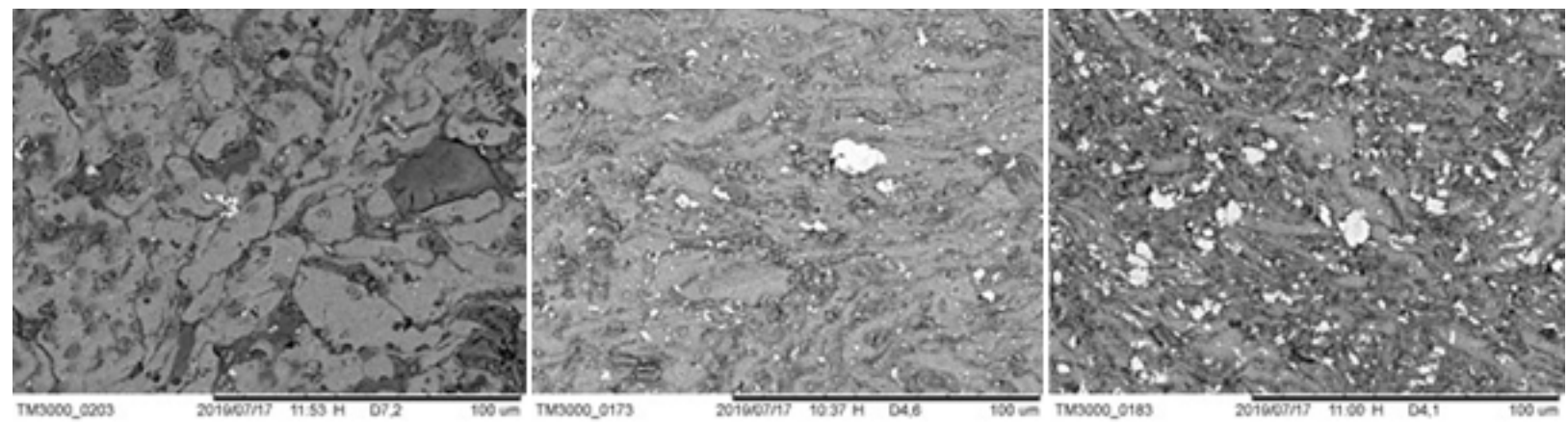

Figura 7. MEV do compósito sinterizado com reforço de 5\% de Alumina com tratamento térmico, seção superficial.. (a) 30min de MAE; (b) 600min de MAE; (c) 120min de MAE. (Autores, 2019)
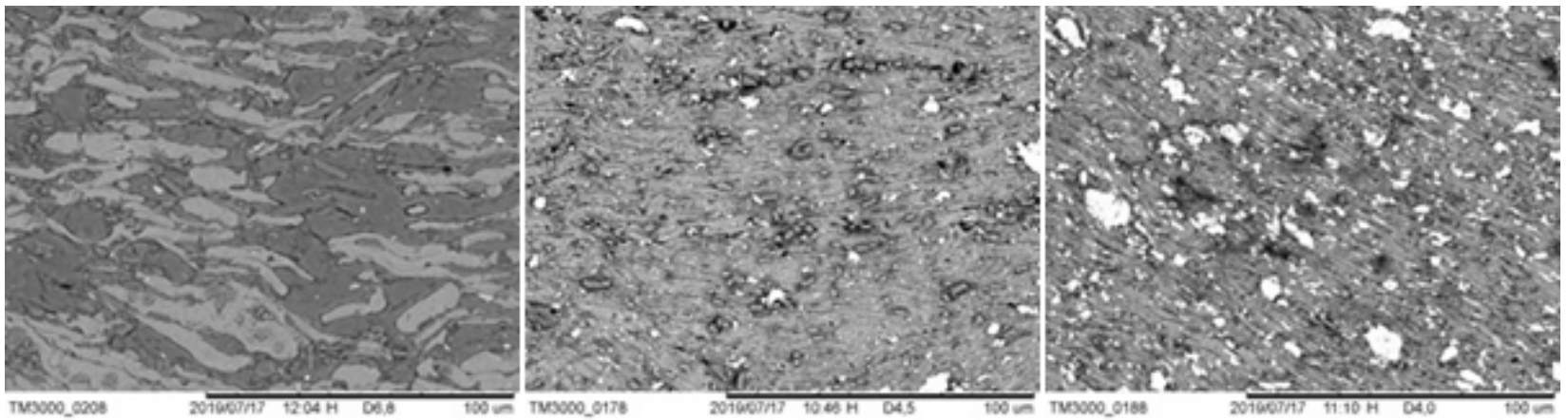

Figura 8. MEV do compósito sinterizado com reforço de 5\% de Alumina com tratamento térmico, seção transversal. (a) $30 \mathrm{~min}$ de MAE; (b) 600min de MAE; (c) 120min de MAE. (Autores, 2019)

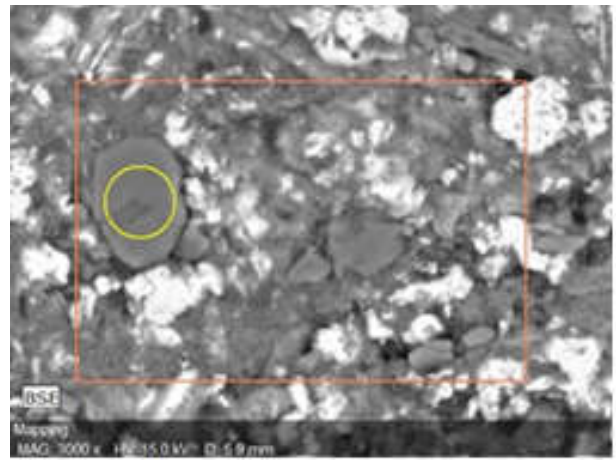

Spectrum: Point

Element AN Series norm. C Atom. C

[wt. : ] [at. : ]

Aluminium 13 K-series $56.71 \quad 43.72$

Oxygen 8 K-series $43.29 \quad 56.28$

Total: $100.00 \quad 100.00$

Figura 9. EDS do compósito sinterizado com reforço de $10 \%$ de Alumina com tratamento térmico, identificando o reforço cerâmico (Autores, 2019)

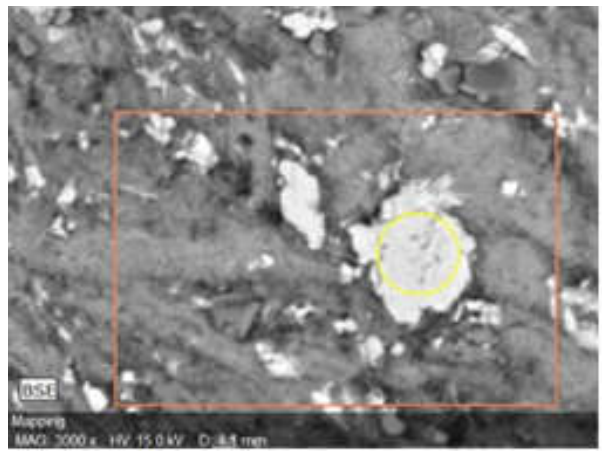

\begin{tabular}{|c|c|c|c|c|}
\hline \multirow{2}{*}{$\begin{array}{l}\text { Spectrum: } \\
\text { Element }\end{array}$} & \multicolumn{4}{|c|}{ Point } \\
\hline & AN & Series & $\begin{array}{r}\text { norm. C } \\
\text { [wt. } \frac{\text { s] }}{6}\end{array}$ & $\begin{array}{l}\text { Atom. C } \\
\text { [at. } \frac{\text { z }]}{}\end{array}$ \\
\hline Aluminium & 13 & $\mathrm{~K}$-series & 59.98 & 72.55 \\
\hline Iron & 26 & K-series & 35.82 & 20.93 \\
\hline Oxygen & 8 & K-series & 2.75 & 5.60 \\
\hline Chromium & 24 & $\mathrm{~K}$-series & 1.46 & 0.91 \\
\hline & & Total: & 100.00 & 100.00 \\
\hline
\end{tabular}

Figura 10. EDS do compósito sinterizado com reforço de $10 \%$ de Alumina com tratamento térmico, identificando precipitado $\mathrm{Al}_{3} \mathrm{Fe}$ (Autores, 2019) 
foi possível analisar que tal elemento químico colaborou para a formação de fases endurecedoras após o tratamento térmico. Com base na razão entre os pesos atômicos (at.\%) do $\mathrm{Al}$ e do Fe foi obtido o valor de 3,5 sugerindo a presença da fase $\mathrm{Al}_{3} \mathrm{Fe}$, no precipitado mostrado na Figura 10. Já na amostra da Figura 11, o valor da razão é de 6 , o que leva a sugerir a presença do precipitado $\mathrm{Al}_{6} \mathrm{Fe}$. Os precipitados encontrados também são relatados no trabalho de Leite (2019). reforço de $30 \mathrm{~min}$ para $60 \mathrm{~min}$ de moagem e com $15 \%$ de reforço de 60min para 120min de moagem, porém a redução de dureza foi só em $7 \%$ e $4 \%$, respectivamente. Segundo Morais (2018) quanto mais refinado o material, ou seja, maior o tempo que o material passa sendo processado, melhor foram os resultados de densidade e dureza. As análises anteriores de MO e MEV mostra a influencia do processamento na redução da granulometria do material e consequente aumento na dureza. Ainda em relação às amostras sem
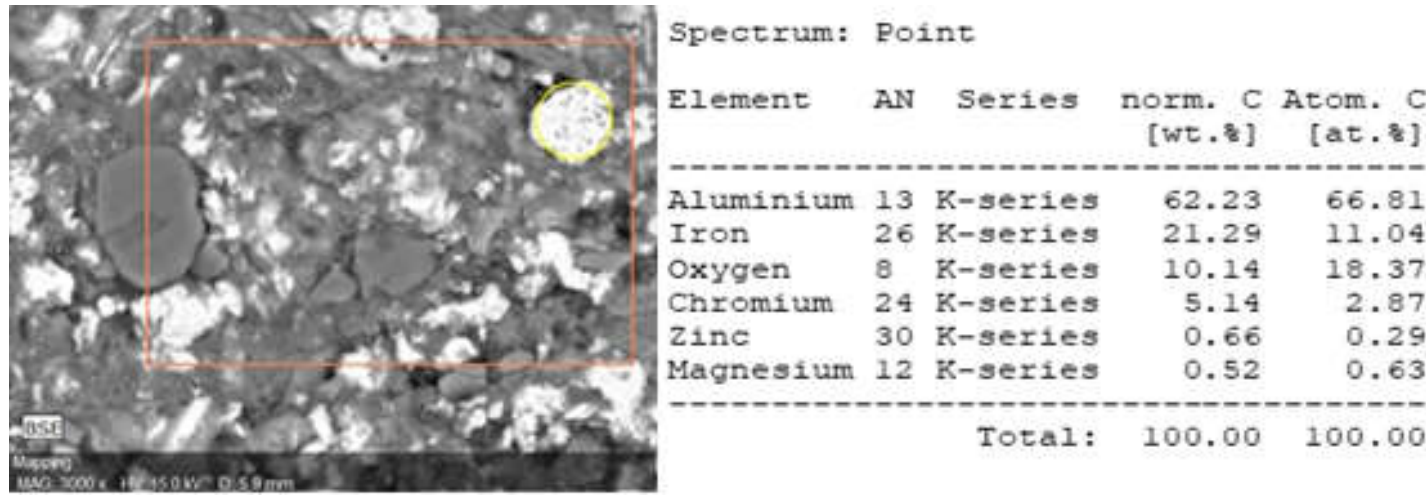

Figura 11. EDS do compósito sinterizado com reforço de $10 \%$ de Alumina com tratamento térmico, identificando precipitado $\mathrm{Al}_{6} \mathrm{Fe}$ (Autores, 2019)

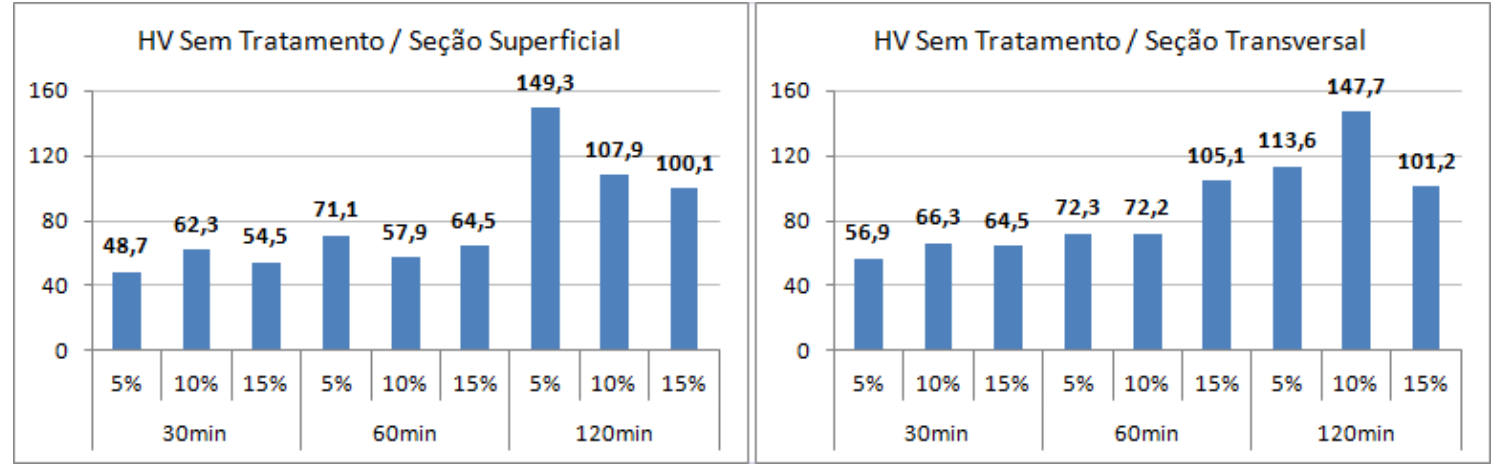

Figura 12. Resultados da dureza Vickers para os compósitos sem tratamento térmico. (Autores, 2019)

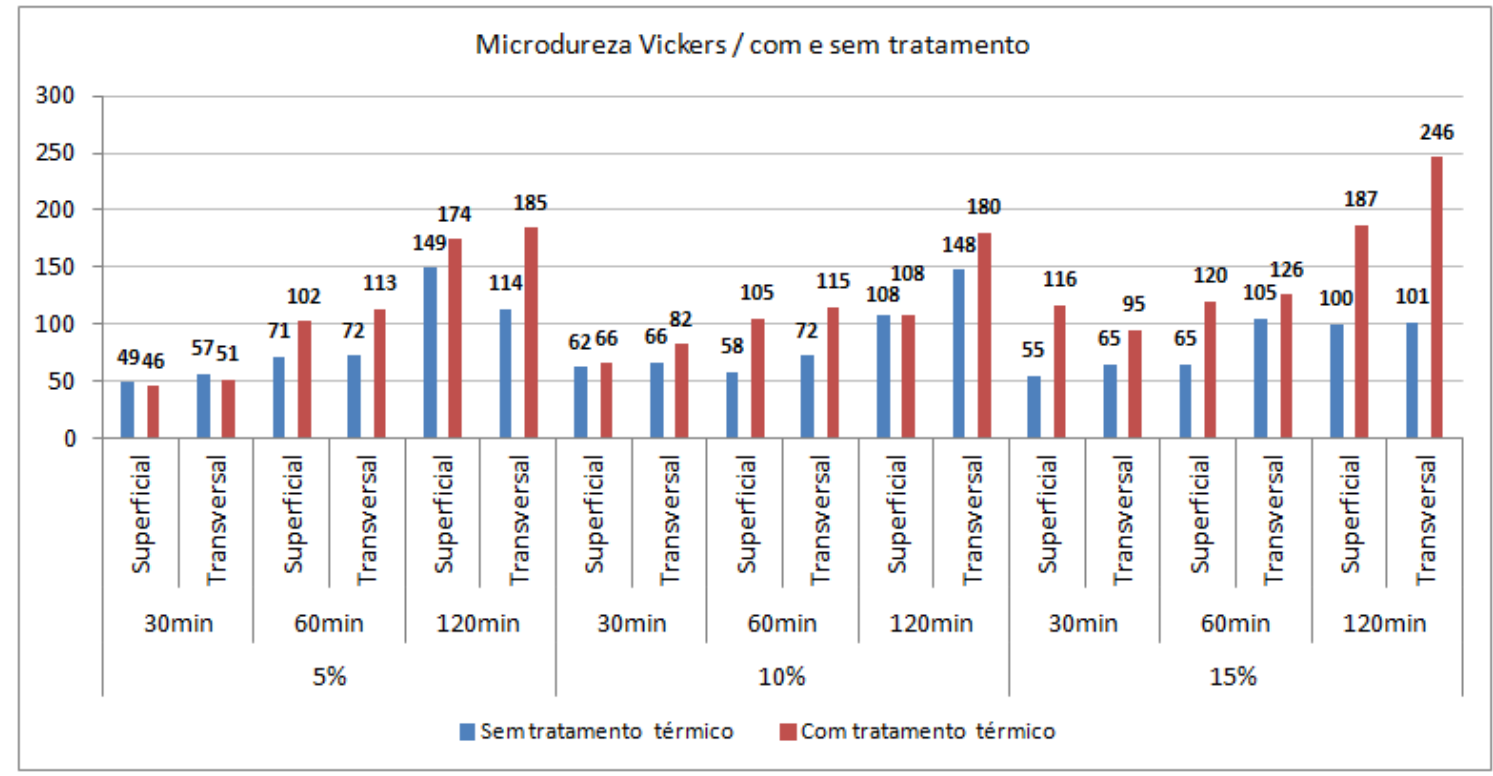

Figura 13. Resultados da dureza Vickers para os compósitos sem e com tratamento térmico. (Autores, 2019)

HV dos Sinterizados Com e Sem Tratamento Térmico: Os resultados da Microdureza Vickers (HV) para as amostras sem tratamento estão mostrados graficamente na Figura 12 para uma melhor visualização dos dados. Nestas à medida que o tempo de moagem aumenta, independente da concentração de reforço, a sua dureza aumenta. Esse fato ocorreu exceto nas amostras com $10 \%$ de tratamento térmico, para concentrações variadas de reforço, não houve diferenças significativas de dureza e nem foi identificado um padrão, apresentando variabilidade no comportamento. Na figura 13 são comparados os resultados de dureza antes e após a solubilização e envelhecimento, verifica-se que as amostras que ganharam mais dureza proporcionalmente foram as que continham maior 
concentração de reforço (15\%) e apenas na amostra com 5\% de reforço e 30min de processamento a dureza foi reduzida, possivelmente por uma condição de superenvelhecimetno. De modo geral o tratamento térmico foi eficaz em melhorar a dureza dos compósitos e assim como nas amostras sem tratamento as maiores durezas das amostras tratadas ocorreram nos sinterizados processados por $120 \mathrm{~min}$.

\section{CONCLUSÕES}

A metalurgia do pó e a moagem de alta energia se mostraram técnicas eficazes na redução da granulometria e na fabricação dos materiais compósitos em estudo, gerando uma microestrutura homogênea entre matriz e reforço. Uma característica muito representativa da aplicação dessa técnica é a formação de uma estrutura lamelar obtida e mais visível na seção transversal. Na aplicação da técnica de MAE, aumentando-se o tempo de moagem pode-se chegar a durezas mais elevadas, pois quanto maior o tempo de moagem, menor os grãos e maior número de contornos. Neste trabalho o reforço cerâmico de Alumina não contribuiu significativamente para o endurecimento da amostra sem Tratamento Térmico, sendo a principal contribuição o aumento do tempo de processamento. Apesar de todo o cuidado para não haver contaminação das amostras, $\mathrm{Na}$ metodologia aplicada o processamento dos pós na jarra e esferas cria um contato direto entre os mesmos, havendo contaminação intrínseca ao processo. No caso, como foi utilizado mídia de moagem de aço inox, houve o surgimento do Ferro ( $\mathrm{Fe}$ ), que não constitui na composição dos materiais iniciais. O tratamento térmico realizado nas amostras de material compósito foi eficiente, aumentando sua dureza pela geração de precipitados endurecedores. Não houve um padrão de crescimento, no entanto, as amostras de $15 \%$ de reforço cresceram mais em proporção e como já esperado, as amostras de $120 \mathrm{~min}$ de moagem continuam a apresentar maior dureza em valor. É valido salientar que, a variação de parâmetros de tempo de processamento, composição e condições de tratamento térmico podem levar a resultados não esperados, como superenvelhecimento, e consequente redução da dureza.

Agradecimentos: Os autores agradecem à Universidade Federal de Pernambuco (UFPE), Departamento de Engenharia Mecânica, Programa de Pós-Graduação em Engenharia Mecânica (PPGEM), CNPq, CAPES e FACEPE.

\section{REFERÊNCIAS}

Araujo Filho, O. O.; Araujo, E. R.; Lira, H. M.; Gonzalez, C. H.; Silva, N. D.; Urtiga Filho, S. L., 2017. Manufacturing of AA2124 Aluminum Alloy Metal Matrix Composites Reinforced by Silicon Carbide Processed by Powder Metallurgy Techniques of High Energy Ball Milling and Hot Extrusion. Materials Science Forum, v. 899, p. 25-30.
Araujo Filho, O.O., Moura, A.D.A., Araujo, E.R., Santos, M.J., Gonzalez, C.H. e Silva, F.J., 2016, "Manufacturing and characterization of AA1100 aluminum alloy metal matrix composites reinforced by silicon carbide and alumina processed by powder metallurgy". Materials Science Forum. ISSN: 16629752, vol. 869, p 447-451.

Araujo Filho, O. O., 2006. Estudo comparativo de aços rápidos AISI M3:2 produzidos por diferentes processos de fabricação. Tese de doutorado. Instituto de Pesquisas Energéticas e Nucleares USP, São Paulo.

Barbosa, C., 2014. Metais não ferrosos e suas ligas: microestrutura, propriedades e aplicações. E-papers, Rio de Janeiro.

Bezerra Junior, C. A.; Araújo de Moura, A. D.; Araujo, E. G.; Santos, M. J.; Melo, L. G. T. C.; Araujo Filho, O. O., 2014. Síntese e caracterização de compósitos de matriz metálica da liga AA2124 com reforço particulado de nitreto de silício através de técnicas de metalurgia do pó. In: $21^{\circ}$ Congresso Brasileiro de Ciência e Engenharia de Materiais, Anais de congresso, Cuiabá.

Callister, W. D.; Rethwisch, D. G., 2012. Ciênciae engenharia de materiais: Uma introdução. LTC Editora, Rio de Janeiro, $8^{\text {a }}$ Edição.

Chiaverini, V., 1992. Metalurgia do pó: Técnica e produtos. Editora ABM, São Paulo, $3^{\text {a }}$ edição.

Leite, M. M., 2019. Estudo de tratamento térmico de solubilização e envelhecimento do compôs/ito de matriz metálica da liga de aluminio AA7075 reforçada por carboneto de nióbio. Trabalho de conclusão de curso. Universidade Federal de Pernambuco, Recife.

Morais, B., 2018. Estudo da influência do tempo de moagem de alta energia na microestrutura e propriedades do compósito $\mathrm{Al}_{2} \mathrm{O}_{3^{-}}$ $10 \%$ pi. Trabalho de conclusão de curso. Universidade Federal do Rio Grande do Norte, Natal.

Souza, J. R. P.; Peres, M. M. P., 2016. Análise microestrutural de pó de alumínio sinterizado obtido pela moagem de alta energia de latas de bebidas. In: $22^{\circ}$ Congresso Brasileiro de Ciência e Engenharia de Materiais, Anais de congresso, Natal.

Suryanarayana, C., 2001. Mechanical alloying and milling. Progress in Materials Science, v. 46, p. 1-184.

Xavier, E. I. V.; Fernandes, L. E.; Nascimento, D. M.; Silva Júnior, M. E.; Zarzar, S. T.; Araujo, E. R.; Araujo Filho, O. O., 2019. Reaproveitamento de cavacos de usinagem através da moagem de alta energia para a fabricação e caracterização de pós metálicos da liga de alumínio AA6061. In: $74^{\circ}$ Congresso Anual da ABM, Anais de Congresso, São Paulo. 